\title{
Erratum to: Assessing the sensitivity of treatment effect estimates to differential follow-up rates: implications for translational research
}

\author{
Beth Ann Griffin • Daniel F. McCaffrey • Rajeev Ramchand • \\ Sarah B. Hunter $\cdot$ Marika Suttorp Booth
}

Published online: 26 September 2012

(C) Springer Science+Business Media, LLC 2012

\section{Erratum to: Health Serv Outcomes Res Method (2012) 12:84-103 DOI 10.1007/s10742-012-0089-7}

The revised version of "Acknowledgment" section is presented in this erratum.

Acknowledgments The development of this article was supported by the Center for Substance Abuse Treatment (CSAT), Substance Abuse and Mental Health Services Administration (SAMHSA) contract \#270-07-0191 using data provided by the following grantees: Cannabis Youth Treatment (Study: CYT; CSAT/SAMHSA contracts \#270-97-7011, \#270-00-6500, \#2702003-00006 using data provided by the following grantees: TI-11317, TI-11321, TI-11323,TI11324) and Effective Adolescent Treatment (Study: EAT; CSAT/SAMHSA contracts \#277-006500, \#270-2003-00006 using data provided by the following grantees: TI11317, TI11321, TI11323, TI3234, TI-15413, TI-15433, TI-15447, TI-15461, TI-15467, TI-15475, TI-15478, TI15479, TI-15481, TI-15483, TI-15486, TI-15511, TI-15514, TI-15545, TI-15562, TI-15670, TI-15671, TI-15672, TI-15674, TI-15678, TI-15682, TI-15686, TI-15415, TI-15421, TI-15438, TI-15446, TI-15458, TI-15466, TI-15469, TI-15485, TI-15489, TI-15524, TI-15527, TI-15577, TI-15584, TI-15586, TI-15677). The authors thank these grantees and their participants for agreeing to share their data to support this secondary analysis. The opinions about this data are those of the authors and do not reflect official positions of the government or individual grantees.

The online version of the original article can be found under doi:10.1007/s10742-012-0089-7.

B. A. Griffin $(\bowtie) \cdot$ R. Ramchand

RAND Corporation, 1200 South Hayes Street, Arlington, VA 22202,

USA

e-mail: bethg@rand.org

D. F. McCaffrey

RAND Corporation, 4570 Fifth Avenue, Suite 600, Pittsburgh, PA 15213, USA

S. B. Hunter · M. Suttorp Booth

RAND Corporation, 1776 Main Street, P.O. Box 2138, Santa Monica, CA 90407, USA 